\title{
Polypyrazolylborate complexes of the lanthanides: structure, optics and materials
}

\author{
Seema S. S. Pillai, Roman Kresinski, Emil Bojarski, and Peter J. S. Foot \\ Department of Materials Science, School of Pharmacy and Chemistry, Kingston University, UK, Kingston-upon- \\ Thames, Penrhyn Road, E-mail: r.kresinski@kingston.ac.uk
}

\begin{abstract}
We report the synthesis and characterisation of monomeric [ $\left.\mathrm{LnTp}_{2}\left(\mathrm{O}_{2} \mathrm{CCH}=\mathrm{CHCH}\right)_{3}\right](\mathrm{Ln}$ $=\mathrm{Ce}-\mathrm{Ho}$, except Pm) and dimeric $\left[\mathrm{LnTp}\left(\mathrm{O}_{2} \mathrm{CCH}=\mathrm{CHR}\right)_{2}\right]_{2}\left(\mathrm{R}=\mathrm{CH}_{3}, \mathrm{Ln}=\mathrm{Ho}-\mathrm{Lu} ; \mathrm{R}=\mathrm{C}_{6} \mathrm{H}_{5}, \mathrm{Ln}=\mathrm{Ce}-\right.$ $Y$, except Pm), along with their co-polymerisations with styrene and methyl methacrylate. The structures and some optical properties of the lanthanide complexes and co-polymers are presented.
\end{abstract}

Keywords - lanthanide, lanthanon, polypyrazolylborate, polystyrene, polymethylmethacrylate, copolymer, luminescence.

\section{Introduction}

The inclusion of $\left(\mathrm{Ln}^{3+}\right)$ ions into polymers has the potential of the production of processible materials with magnetism, or optical properties. We sought to make polymeric species in which lanthanide ions were separated, so as to avoid quenching of magnetism or optical emission. In order to achieve this, we initially pursued the synthesis of heteroleptic hydrotrispyrazolylborate-crotonate and cinnamate complexes $\left[\mathrm{LnTp}_{2}\left(\mathrm{O}_{2} \mathrm{CCH}=\mathrm{CHCH}_{3}\right)\right](\mathrm{Ln}=$ Ce-Ho, except Pm $)$ and $\left[\mathrm{LnTp}\left(\mathrm{O}_{2} \mathrm{CCH}=\mathrm{CHR}\right)_{2}\right]_{2}\left(\mathrm{R}=\mathrm{CH}_{3}, \mathrm{Ln}=\mathrm{Ho}-\mathrm{Lu} ; \mathrm{R}=\mathrm{C}_{6} \mathrm{H}_{5}, \mathrm{Ln}=\mathrm{Ce}-\mathrm{Yb}\right.$, except $\mathrm{Pm}$ ), as potential copolymerisation monomers. Firstly, these species are resistant to ligand redistribution reactions[1], which makes the stoichiometry of lanthanide to double bond a reliable $1: 1$ or 1:2 ratio, simplifying any understanding of kinetics. Secondly, the lanthanide ion is encapsulated within an environment, for which it has a greater affinity than a non-polar one. It was thus our anticipation that the lanthanide ions would remain in predictably-distant 'island' points in any product polymer, wherefrom they would migrate only under great stress.

\section{Initial Findings}

The $\left[\mathrm{LnTp}_{2}\left(\mathrm{O}_{2} \mathrm{CCH}=\mathrm{CHCH}_{3}\right)\right](\mathrm{Ln}=\mathrm{Ce}-\mathrm{Ho}$, except $\mathrm{Pm})$ and $\left[\mathrm{LnTp}\left(\mathrm{O}_{2} \mathrm{CCH}=\mathrm{CHR}\right)_{2}\right]_{2}(\mathrm{R}$ $=\mathrm{CH}_{3}, \mathrm{Ln}=\mathrm{Ho}-\mathrm{Lu} ; \mathrm{R}=\mathrm{C}_{6} \mathrm{H}_{5}, \mathrm{Ln}=\mathrm{Ce}-\mathrm{Yb}$, except $\mathrm{Pm}$ ) complexes, fully characterised by infrared spectroscopy and mass spectrometry, and representative examples were characterised by single-crystal X-ray means. Copolymers of the above classes were synthesised and studied optically, by both emissive and absorptive means. Some of them showed productive energy transfer to, and re-emission from, the lanthanide ion.

\section{Conclusion}

Selected lanthanide species were copolymerised with styrene and methylmethacrylate, and some of the resulting materials showed promise as processible materials showing promise in materials applications.

\section{References}

[1] M. A. J. Moss, C. J. Jones and A. J. Edwards, Dalton Trans., 1989, 1393. 